\title{
Content of metals and organic acids from experimental sparkling white wine
}

\author{
Mihai Cristian Focea ${ }^{1}$, Camelia Elena Luchian ${ }^{1}$, Ana Maria Moroşanu${ }^{1}$, Marius Niculaua ${ }^{2}$, Valeriu V. Cotea ${ }^{1, a}$, \\ Gheorghe Odăgeriu ${ }^{2}$, and Cătălin Ioan Zamfir ${ }^{2}$ \\ ${ }^{1}$ The University of Agricultural Sciences and Veterinary Medicine, Mihail Sadoveanu Alley, 3, Iaşi 700490, Romania \\ ${ }^{2}$ Research Centre for Oenology of Romanian Academy - Iaşi Branch, Mihail Sadoveanu Alley, 9, Iaşi 700490, Romania
}

\begin{abstract}
This work is focused on the study of the influence of different strains of yeasts on the concentration of organic acids, metallic content, and other physical-chemical parameters from experimental sparkling white wines produced by traditional method (bottle fermented). This study was required due to climatic conditions varying from year to year, generating grape harvests with very high alcoholic potential, and very low values for total acidity. In this case, a Muscat Ottonel grape must was used and passed by a reverse osmosis process. The obtained permeate was mixed with a calculated amount of the concentrate to generate a must with a potential of $10.5 \%(\mathrm{v} / \mathrm{v})$ alcohol, in order o to obtain the base wine for the second fermentation. After fermentation, the wine was treated to get tartaric, protein and microbiological stabilization. For the second fermentation four different strains of yeast species Saccharomyces cerevisiae were used. Bottle fermentation and storage was performed at a constant temperature of approximately $12^{\circ} \mathrm{C}$. After six months of storage, sparkling wine samples were analyzed. The metal content was determined using AAS method, and organic acid concentration was determined by a HPLC method. The main physical-chemical characteristics were determined (alcohol concentration, total acidity, volatile acidity, total dry extract, free $\mathrm{SO}_{2}$, total $\mathrm{SO}_{2}$, density, $\mathrm{pH}$, conductivity) based on OIV methods. The results obtained indicated significant differences of the analyzed parameters.
\end{abstract}

\section{Introduction}

Sparkling wines obtain by the traditional method and here it can be mentioned cava wines (Spain) and champagne wines (France) have been scarcely studied in the literature of the field. The traditional method of obtaining sparkling wines consists of a second fermentation process. The base wine elaborated in a first phase is left to undergo a second alcoholic fermentation, inside a sealed bottle by adding tirage liqueur and yeasts, followed by ageing on yeast lees under anaerobic conditions for several months [1].

The composition of a sparkling wine and in general of a wine is due to many factors related to the specific production area such as: grape variety, soil, climate, yeast, wine making practices and not only. All of this factors have an important influence on the quality of wine and they also have a major role in the characterization and differentiation of wines $[2,3]$.

The mineral content in wines has been extensively studied and reported due to the implications on different levels such as: sensorial, hygienic, dietetic, toxicological [4]. Furthermore this type of studies helps to characterize and to differentiate the wines from the geographical point of view when reliable chemical analyses techniques in combination with modern chemometrical methods are used [5-8].

The levels of organic acids in wines and in general of the volatile component are strongly influenced by the dynamics and the activity of the indigenous or the

a e-mail: vvcotea@yahoo.com inoculated yeasts [9]. In wines, organic acids have a major role for the composition, the stability and the organoleptic qualities and their preservative proprieties enhance the microbiological and the physicochemical stability [10].

Reverse osmosis (RO) is a technology that uses a semi permeable membrane to remove ions, molecules and larger particles from different liquids. In reverse osmosis, an applied pressure is used to overcome osmotic pressure a colligative property, which is driven by chemical potential differences of the solvent, a thermodynamic parameter. In the winemaking industry it is desired to obtain a wine from extremely ripe grapes in order to create a wine with a developed sensory palette, but in this case occurs the problem of obtaining wines with a high alcoholic strength [11-14].

Thus, in order to avoid this type of situations reverse osmosis is applied and in this case the level of alcohol is reduced without major changes on the fruit flavors and other elements in the wine.

\section{Materials and methods}

\subsection{Must samples}

The present study was carried out on four samples of sparkling wines obtained from Muscat Ottonel juice/must. Muscat Ottonel is a younger and less-distinguished member of the broader Muscat family and it is considered to be a clone obtained from the crossed process of Chasselas and Muscat Ingram [15]. 
The must and implicitly the wines obtained from the Muscat Ottonel must are characterized by a floral aroma with fruity notes such as apricot and quince. Noteworthy is that the juice of Muscat Ottonel are suitable for obtaining both dry and sweet wines. Concerning the present study the raw material - the must was obtained from grapes of Muscat Ottonel that were harvest in 2015 at full maturity from Iaşi vineyard.

\subsection{Wine samples}

The sparkling wine samples taken in the experiment were produced in the micro-winery belonging to the Oenological department of the University of Agricultural Sciences and Veterinary Medicine of Iasi.

It is a must to emphasize the fact that the samples covered by this scientific study were obtained by applying the classical method. This method consists of a secondary bottle fermentation of the wine raw material, followed by the removal of impurities by riddling and disgorgement operations.

The harvest of grapes along with the primary fermentation proceeds have gone as with any still wine. The still wine produced becomes in this way the basewine to be used in the next step. It is necessary to mention the fact that a reverse osmosis process was applied to the initial must, then the obtained permeate and concentrate was mixed in a variable ratio to generate a must with a potential of $10.5 \%(\mathrm{v} / \mathrm{v})$ alcohol, followed by the typical fermentation process.

The second fermentation is induced by adding four different yeasts mixed with a calculated amount of the concentrate must (called "tirage liqueur"). The sugar added with the "tirage liqueur" provides food for the yeast and is entirely consumed during the secondary fermentation and has no effect on the "sweetness" of the final product. At this time the bottle is capped with a crown cap (the same as a beer bottle) and stored in a cellar in the horizontal position to age.

After the completion of the aging process, the bottle is submitted to a removing operation of the dead yeast, this process being known as riddling. At this stage the bottles are placed on special racks at a $45^{\circ}$ angle with the cork pointed down and occasionally the bottles are slightly shaken. After, the position of the bottles is changed being pointed straight down with the sediment in the neck of the bottle.

The disgorging operation consists in a frizzing process of the neck bottles that are still pointed down and after that the bottles are turned upright and the cap is removed. In this way the pressure in the bottle will eliminate the lees.

Immediately after disgorging and before final corking, the wine levels from the bottles is completed and the liqueur for dosage is added, in order to obtain certain sensory characteristics and the various types of sparkling wine

\subsection{Reagents for the fermentation process}

For the fermentation process the most important factor is the type of the yeasts that were used. Thus, the yeasts are becoming the experimental factor helping to differentiate samples regarding the quality of the wine obtained given by: aromatic compounds, metals content, acids content, color and the determination of the amino acids. The samples are: V0- the blank sample, V1- the type I of yeast are used, V2- the type 2 of yeast are used, V3- the type 3 of yeast are used, V4- the type 4 of yeast are used. It is also necessarily to underline the fact that the yeasts that were used for this experiment are IOC products.

After the decarbonisation operation, each sample of wine was submitted to the following analyses: sulfur dioxide, volatile acidity, total acidity, alcoholic strength, reducing substances, total dry matter and non reducing substances. The analyses were done according to OIV methods and the specific literature [10].

\subsection{The quantification of metals in the wines samples using an Agilent MP-AES 4200 system}

The analyzed samples were diluted in order to reduce the salinity of the samples below $1 \%$. The technique employed doesn't need the mineralisation of the samples or the addition of ionisation buffers. The measurements were performed using an Agilent MP-AES 4200 (Microwave Plasma-Atomic Emission Spectrometer) system equipped with the standard sample introduction system consisting of the OneNeb nebulizer, double pass cyclonic spray chamber and easy fit torch.

The Agilent SPS-3 auto sampler was used to deliver samples to the instrument allowing unattended operation. The selection of optimal lines depended on wavelengths that were free from spectral interference and matched the appropriate sensitivity. Concerning the interferences on the background and spectral level can be corrected for using the MP software. The read time for all samples is 3 seconds and all others instrument operating parameters are presented in Table 1.

\subsection{The determination of organic acids of the wine samples}

The analysis of the organic acids was performed by using a HPLC Shimadzu series 20 system. The samples were filtered through a $28 \mathrm{~mm}$ nylon $60.45 \mu \mathrm{m}$ syringe cartridge according to the modified methodology described in the method MA-E-AS313-04-ACIORG by O.I.V. standards. A $5 \mu \mathrm{L}$ volume of sample or standard was injected through two analytical columns (YMC-Triart C18 multistage hybrid group's $3 \mu \mathrm{m} 150 \times 4.6 \mathrm{~mm} 120 \AA$ ) at a flow rate of $0.9 \mathrm{~mL} / \mathrm{min}$. using a solution of sulphuric acid adjusted to $1.3 \mathrm{pH}$ value. Columns temperatures are maintained to $45^{\circ} \mathrm{C}$ for the entire run. The quantification of compounds is done at certain wavelength for each organic acid.

\section{Results and discussion}

The general physic-chemical parameters of the analyzed sparkling wine samples are presented in Table 2. It is necessarily to mention the fact that in the obtaining process of sparkling wines was used the same raw-material-wine and possible differences could result from using different types of fermentation yeasts.

Comparing the sparkling wine samples, visible differences can be observed between the blank samples and the samples treated with specific yeasts. Thus, the values of the alcoholic strength of the analyzed samples ranged 
Table 1. Operating parameters for Agilent MP-AES 4200 system.

\begin{tabular}{|c|c|c|c|c|c|}
\hline Element & $\begin{array}{c}\text { Wavelength } \\
\lambda(\mathrm{nm})\end{array}$ & $\begin{array}{c}\text { Nebulizer } \\
\text { Flow }(\mathrm{L} / \mathrm{min})\end{array}$ & $\begin{array}{c}\text { Air Injection } \\
\text { Flow Rate }\end{array}$ & $\begin{array}{c}\text { Optimal dilution } \\
\text { factor of wine }\end{array}$ & $\begin{array}{c}\text { Linear domain } \\
\text { for } \mathrm{r}^{2} \geq 0.995\end{array}$ \\
\hline $\mathrm{Zn}$ & 213.857 & 0.45 & medium & $1 / 10$ & $10-200 \mathrm{ppb}$ \\
\hline $\mathrm{Fe}$ & 371.993 & 0.65 & high & $1 / 10$ & $3-500 \mathrm{ppb}$ \\
\hline $\mathrm{Cu}$ & 324.754 & 0.7 & high & $1 / 10$ & $3-2000 \mathrm{ppb}$ \\
\hline $\mathrm{Ni}$ & 352.454 & 0.7 & high & $1 / 10$ & $5-2000 \mathrm{ppb}$ \\
\hline $\mathrm{Pb}$ & 405.781 & 0.75 & high & $1 / 10$ & $25-2000 \mathrm{ppb}$ \\
\hline $\mathrm{Mn}$ & 403.076 & 0.9 & high & $1 / 10$ & $3-500 \mathrm{ppb}$ \\
\hline $\mathrm{Mg}$ & 285.213 & 0.9 & medium & $1 / 100$ & $5-2000 \mathrm{ppb}$ \\
\hline $\mathrm{Ca}$ & 396.847 & 0.6 & high & $1 / 100$ & $25-300 \mathrm{ppb}$ \\
\hline $\mathrm{Na}$ & 589.592 & 0.95 & high & $1 / 100$ & $0.25-5 \mathrm{ppm}$ \\
\hline $\mathrm{K}$ & 769.897 & 0.75 & high & $1 / 100$ & $0.1-5 \mathrm{ppm}$ \\
\hline
\end{tabular}

Table 2. Quality parameters of the wine raw-material and of the sparkling wines obtained.

\begin{tabular}{|l|l|l|l|l|l|l|l|l|}
\hline Samples & $\mathbf{1}$ & $\mathbf{2}$ & $\mathbf{3}$ & $\mathbf{4}$ & $\mathbf{5}$ & $\mathbf{6}$ & $\mathbf{7}$ & $\mathbf{8}$ \\
\hline Blank sample-V0 & 0.9921 & 6.2 & 0.33 & 10.3 & 17.2 & 70.7 & 15.2 & 2.8 \\
\hline Sample V1 & 0.9905 & 6.7 & 0.32 & 11.6 & 5.12 & 56.3 & 14.5 & 3.1 \\
\hline Sample V2 & 0.9908 & 6.9 & 0.29 & 11.3 & 5.12 & 48.6 & 13.3 & 3.0 \\
\hline Sample V3 & 0.9906 & 6.9 & 0.26 & 11.6 & 5.12 & 51.2 & 13.5 & 3.0 \\
\hline Sample V4 & 0.9907 & 6.6 & 0.31 & 11.3 & 7.68 & 64.0 & 14.3 & 3.0 \\
\hline
\end{tabular}

1- density; $\mathbf{2}$ - total acidity (g tartaric acid/L); 3- volatile acidity (g acetic acid/L);

4- alcohol strength $(\%) ; \mathbf{5}$ - free $\mathrm{SO}_{2}(\mathrm{mg} / \mathrm{L}) ; \mathbf{6}$ - total $\mathrm{SO}_{2}(\mathrm{mg} / \mathrm{L})$;

7- Non-reducing extract $(\mathrm{g} / \mathrm{L}) ; 8-\mathrm{pH}$.

Table 3. The alkaline and alkaline-earth metals content in the raw-material wine and in the analyzed sparkling wines.

\begin{tabular}{|c|c|c|c|c|c|}
\hline \multicolumn{2}{|c|}{ Samples } & $\mathbf{K}(\mu \mathrm{g} / \mathrm{L})$ & $\mathbf{C a}(\mu \mathrm{g} / \mathrm{L})$ & $\mathbf{M g}(\mu \mathrm{g} / \mathrm{L})$ & $\mathbf{N a}(\mu \mathrm{g} / \mathrm{L})$ \\
\hline \multicolumn{2}{|c|}{ Blank sample -V0 } & 139,92 & 28,24 & 249,02 & 296,00 \\
\hline \multirow{4}{*}{6 months } & V1 & 553,06 & 124,77 & 28,77 & 37,58 \\
\hline & $\mathbf{V 2}$ & 547,27 & 126,00 & 28,82 & 43,38 \\
\hline & V3 & 545,52 & 126,82 & 28,6 & 40,23 \\
\hline & V4 & 556,61 & 127,27 & 28,57 & 38,02 \\
\hline \multirow{4}{*}{11 months } & V1a & 530,54 & 126,29 & 28,87 & 24,2 \\
\hline & V2a & 552,17 & 124,71 & 28,64 & 21,76 \\
\hline & V3a & 551,09 & 124,62 & 28,36 & 24,78 \\
\hline & V4a & 527,52 & 124,65 & 28,17 & 24,26 \\
\hline
\end{tabular}

between a minimum of $10.34 \%$ for the blank sample and a maximum of $11.6 \%$ for the samples V1 and V3. The dynamic of the alcoholic strength can result from the fermentation process that was "accelerated" for the samples inoculated in the second fermentation stage with specific yeasts.

The density of the samples is correlated with the sugar content of the wines. Furthermore, observing the sugar levels or the reducing substances, the sparkling wine samples can be included in the category brut.

The total acidity that varied from $6.28 \mathrm{~g} / \mathrm{L}$ to $6.9 \mathrm{~g} / \mathrm{L}$ and the volatile acidity that ranged between $0.26 \mathrm{~g} / \mathrm{L}$ and $0.33 \mathrm{~g} / \mathrm{L}$ describe the profile of balanced sparkling wine samples. Generally, the real acidity of the wine or the $\mathrm{pH}$ has an important impact on almost every aspect: color, stability, flavor and also on the rate of the fermentation process. Referring to the analyzed samples this parameter was situated between 2.8 and 3.1 a range that doesn't allow the growth of bad microorganisms.

Detection of the presence of different metals in the blank sample and also in the samples treated with specific yeasts was carried out using an Agilent MP-AES 4200 system. The values of the metals concentrations that were identified in the sparkling wine samples are listed in
Table 2 and Table 3. It is required to mention the fact that the metal analysis of the samples was performed at six months (V1, V2, V3, V4) and at eleven months (V1a, $\mathrm{V} 2 \mathrm{a}, \mathrm{V} 3 \mathrm{a}, \mathrm{V} 4 \mathrm{a})$.

The presence of metals in wine has a double origin: natural and anthropogenic and their concentrations can play a significant role, affecting the consumption and also the conservation of the wines. Sparkling wines quality and in general wines quality depends also on the metal composition since the metallic ions have important roles in the oxide-reductive reactions resulting in wine browning, turbidity, cloudiness and astringency. Most metals are important for efficient alcoholic fermentation. $\mathrm{Ca}, \mathrm{Mg}, \mathrm{K}$ and $\mathrm{Na}$ are implicated in the process of cellular metabolism of yeasts by maintaining the right level of $\mathrm{pH}$ and ionic balance.

Observing Table 3 and Fig. 1, it can be noticed a variability concerning the presence of $\mathrm{Mg}, \mathrm{Ca}, \mathrm{K}$ and $\mathrm{Na}$ in the blank sample and in the samples analysed. So, the concentrations of $\mathrm{K}$ and $\mathrm{Ca}$ register a growth after the storage at six and eleven months, but in the case of $\mathrm{Mg}$ and $\mathrm{Na}$ a considerable decrease is detected.

The composition of metals in wine during fermentation, maturation and storage is not stable. In the fermented 


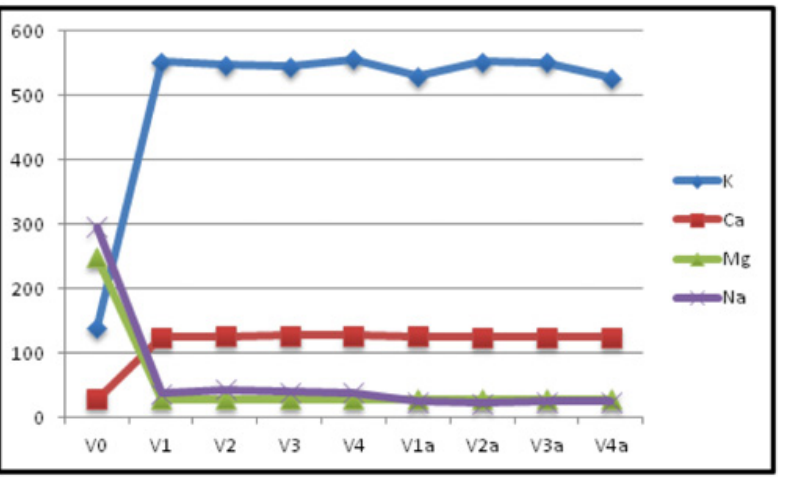

Figure 1. Dynamic of the alkaline and alkaline-earth metals concentrations in the wine raw-material and in the analyzed sparkling wines.

Table 4. Concentrations of $\mathrm{Mn}, \mathrm{Zn}, \mathrm{Fe}, \mathrm{Cu}$ and $\mathrm{Ni}$ in the wine raw-material and in the analyzed sparkling wines.

\begin{tabular}{|c|c|c|c|c|c|c|c|}
\hline \multicolumn{2}{|c|}{ Samples } & $\begin{array}{c}\text { Mn } \\
(\mu \mathrm{g} / \mathrm{L})\end{array}$ & $\begin{array}{c}\mathbf{Z n} \\
(\mu \mathrm{g} / \mathrm{L})\end{array}$ & $\begin{array}{c}\mathbf{F e} \\
(\mu \mathrm{g} / \mathrm{L})\end{array}$ & $\begin{array}{c}\mathbf{C u} \\
(\mu \mathrm{g} / \mathrm{L})\end{array}$ & $\begin{array}{c}\mathbf{N i} \\
(\mu \mathrm{g} / \mathrm{L})\end{array}$ & $\begin{array}{c}\mathbf{P b} \\
(\mu \mathrm{g} / \mathrm{L})\end{array}$ \\
\hline \multicolumn{2}{|c|}{$\begin{array}{l}\text { Blank } \\
\text { sample - } \\
\text { V0 }\end{array}$} & 668,84 & 326,03 & 1214,65 & 188,12 & 128,11 & 206,23 \\
\hline \multirow{4}{*}{$\begin{array}{l}\text { 号 } \\
\text { 兽 } \\
\text { E. }\end{array}$} & V1 & 708,76 & 380,09 & 1619,9 & 118,02 & 144,75 & 449,9 \\
\hline & V2 & 689,83 & 377,53 & 1457,47 & 124,59 & 140,74 & ND \\
\hline & V3 & 696,18 & 387,35 & 1476,17 & 111,3 & 138,88 & ND \\
\hline & V4 & 698,66 & 351,56 & 1433,72 & 113,2 & 145,96 & 558,74 \\
\hline \multirow{4}{*}{ 美 } & V1a & 706,65 & 216,3 & 1704,21 & 154,27 & 143 & 260,77 \\
\hline & V2a & 712,17 & 361,69 & 1536,80 & 152,95 & 146,86 & 135,83 \\
\hline & V3a & 691,24 & 315,8 & 1487,92 & 118,25 & 144,69 & 631,85 \\
\hline & V4a & 701,20 & 212,54 & 1505,59 & 118,66 & 169,14 & 2,46 \\
\hline
\end{tabular}

musts and wines, yeasts consume $\mathrm{Ca}, \mathrm{Cu}, \mathrm{Fe}, \mathrm{K}, \mathrm{Mg}$ and $\mathrm{Zn}$, so usually their concentrations decrease [16].

After the fermentation process, racking of yeasts sediments and other precipitates is used to remove these metals. However, referring to the analyzed samples the concentrations of metals such as: $\mathrm{Zn}, \mathrm{Fe}, \mathrm{Cu}, \mathrm{Ni}, \mathrm{Mn}$ are higher for the samples inoculated with yeasts.

Even more, comparing the concentrations of $\mathrm{Fe}$, $\mathrm{Cu}, \mathrm{Ni}$, and $\mathrm{Mn}$ in the samples $\mathrm{V} 1, \mathrm{~V} 2, \mathrm{~V} 3, \mathrm{~V} 4$ an interesting dynamic is observed (Table 4 and Fig. 2). Thus, the concentrations of these metals have increased with the increasing of the storage period. This phenomenon might suggest the susceptibility of the wine samples to the clouding or sedimentation process as well as flavor deterioration due to the strong catalytic and oxidative proprieties of the cations (especially $\mathrm{Fe}$ and $\mathrm{Cu}$ ). The concentration of $\mathrm{Pb}$ in the analyzed samples weren't represented in Fig. 1 due to the fact that in the case of samples V2 and V3 the presence of this metal wasn't detected by the system and in the case of other samples the presence wasn't pure but interfering with the presence of Fe.

The presence of the main organic acids and their concentrations in the analyzed sparkling wines samples are presented in Table 5. As it was mentioned before for the determination of organic acids a HPLC Shimadzu was used. The organic acids that were the subject of this study were: the malic acid, the tartaric acid, the shikimic acid, the lactic acid, the acetic acid, the citric acid, the succinic acid and fumaric acid.

The acids in wine are one of the essential components in both winemaking and the finished product since they

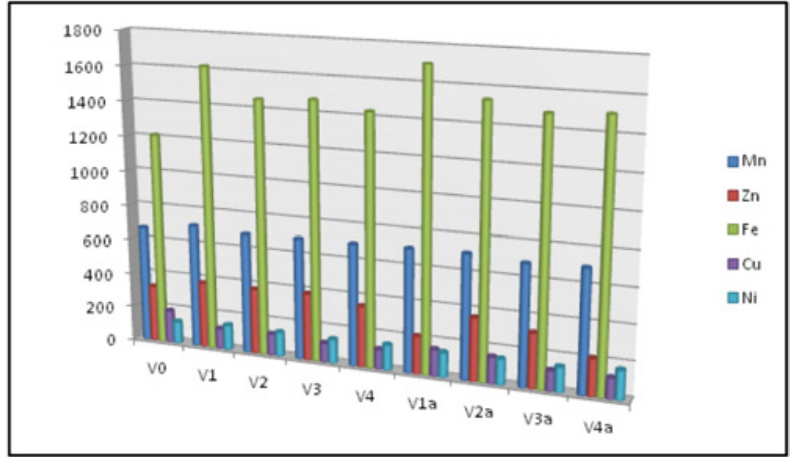

Figure 2. Concentrations of $\mathrm{Mn}, \mathrm{Zn}, \mathrm{Fe}, \mathrm{Cu}$ and $\mathrm{Ni}$ in the wine raw-material and in the analyzed sparkling wines.

have a direct influence on the color, balance and on the taste. In addition the acids present in wines assure the growth and the vitality of yeast during fermentation and also have a protective role against harmful bacteria. When the presence of the organic acids is at the right level a balanced wine is obtain, a wine characterized by a refreshing organoleptic sensation. On the other hand excessive concentrations give the wine a tart or a sour taste.

Malic acid along with the tartaric acid is one of the principal acids found in grapes and wine. In the analyzed samples the higher value was detected in the blank sample and with the storage of the samples a slight decrease was observed. From winemaking perspective the tartaric acid is one of the most important one due to its prominent role in maintaining the stability of the wine and due to its influence on the color and taste of the finished product. Referring to the results this acid varied from a minimum of $0,99 \mathrm{mg} / \mathrm{L}$ for the sample $\mathrm{V} 3 \mathrm{a}$ and a maximum of $5,97 \mathrm{mg} / \mathrm{L}$ for the blank sample. Actually the same tendency of quantitative decrease was observed for most organic acids determined with some minor exceptions such as: fumaric acid, citric acid and malic acid.

As a minor carboxylic acid, shikimic acid can be identified in a wide range of fruits and it can be a great help in establishing the traceability and the authenticity of a wine. In the analyzed sparkling wines the level of this organic acid has suffer a slight decrease with the time of storage, the higher value being registered for the blank sample V0, respectively $15,97(\mu \mathrm{g} / \mathrm{L})$, but a generally decreased was identified at 11 months of storage.

On the other hand observing the dynamic of fumaric acid, an important increase can be noticed with the storage, So, if for the blank sample the level of this acid was somewhere $9,74 \mathrm{mg} / \mathrm{L}$, after six months of storage the quantity of fumaric acid was four times higher and at 11 months a slight decrease was observed.

\section{Conclusions}

Following the results of the physico-chemical characteristics, the considered samples could be included in the category of "brut" sparkling wines.

The metals analysis revealed important differences between the analyzed samples. So, in the case of $\mathrm{K}$ and $\mathrm{Ca}$, the concentrations in the sparkling wines after six months 
Table 5. The organic acids identified in the in the wine raw-material and in the analyzed sparkling wines.

\begin{tabular}{|c|c|c|c|c|c|c|c|c|c|}
\hline \multicolumn{2}{|c|}{ Samples } & $\mathbf{1}$ & 2 & 3 & 4 & 5 & 6 & 7 & 8 \\
\hline \multicolumn{2}{|c|}{ Blank sample -V0 } & 2,84 & 5,97 & 15,97 & 0,36 & 0,85 & 0,45 & 1,07 & 9,74 \\
\hline \multirow{4}{*}{6 months } & V1 & 6,33 & 1,39 & 4,14 & 0,42 & 0,38 & 0,58 & 0,18 & 34,54 \\
\hline & V2 & 6,46 & 1,42 & 4,36 & 0,38 & 0,39 & 0,59 & 0,20 & 40,43 \\
\hline & V3 & 6,35 & 1,40 & 4,27 & 0,38 & 0,38 & 0,58 & 0,31 & 32,31 \\
\hline & V4 & 6,42 & 1,41 & 4,61 & 0,40 & 0,39 & 0,61 & 0,31 & 33,34 \\
\hline \multirow{4}{*}{11 months } & V1a & 6,42 & 1,39 & 4,02 & 0,63 & 0,39 & 0,59 & 0,29 & 32,05 \\
\hline & V2a & 6,63 & 1,42 & 4,29 & 0,60 & 0,38 & 0,57 & 0,30 & 36,84 \\
\hline & V3a & 5,61 & 0,99 & 4,68 & 1,12 & 0,21 & 0,51 & 0,22 & 15,65 \\
\hline & V4a & 6,51 & 1,45 & 4,31 & 0,58 & 0,37 & 0,51 & 0,17 & 31,77 \\
\hline
\end{tabular}

1- malic acid (g/L); 2- tartaric acid (g/L); 3- shikimic acid (mg/L); 4- lactic acid (g/L); 5- acetic acid (g/L); 6- citric acid (g/L); 7- succinic acid (g/L); 8- fumaric acid $(\mu \mathrm{g} / \mathrm{L})$.

of storage has increased as compared to the blank sample and after that suffered a slight decrease.

The levels of $\mathrm{Mg}$ and $\mathrm{Na}$ have registered important decreases at both series of samples, six months and eleven months of storage due to the yeast metabolism. On the other hand, in the case of $\mathrm{Mn}, \mathrm{Zn}, \mathrm{Fe}$ and $\mathrm{Ni}$ the analysis showed a marked increase after six months of storage compared with the raw-material wine. At eleven months the levels of $\mathrm{Mn}$ and $\mathrm{Zn}$ have diminished, but in the case of Fe has augmented probably due to the formation of stable complexes with amino-acids, melanoids.

The level of $\mathrm{Cu}$ has decreased in the samples analyzed after the six months of storage, but later an augmentation was observed. However, it should be stated the fact that the variability of the metals can be influenced by the evolution of $\mathrm{pH}$, the activation of prosthetic metallo-enzyme and the ionic balance.

\section{References}

[1] F. Torchio, S. Río Segade, V. Gerbi, E. Cagnasso, L. Rolle, Food Research International 44, 729-738 (2011)

[2] R. Lara, S. Cerutti, J.A. Salonia, R.A. Olsina, L.D. Martínez, Food Chem. Toxicol. 43, 293-297 (2005)

[3] M. Urbano, M.D. Luque, P.M. de Castro, J.GarcíaOlmo Pérez, M.A. Gómez-Nieto, Food Chem. 97, 166-175 (2006)
[4] M. López-Arttıguez, A.M. Cameán, M. Repetto, J. AOAC Int. 79, 1191-1197 (1996)

[5] Thiel, K. Danzer, Fresenius J. Anal. Chem. 357, 553-557 (1997)

[6] L. Sun, K. Danzer, G. Thiel, Fresenius J. Anal. Chem. 359, 143-149 (1997)

[7] K. Danzer, D. García, G. Thiel, M. Reichenbacher, Am. Lab. 26-34 (1999)

[8] W.U. Kwan, B.R. Kowalski, J. Food Sci. 43, 1320-1323 (1978)

[9] P. Hernandez-Orte, J. F. Cacho, V. Ferreira, J. Agric. Food Chem. 50, 2891-2899 (2002)

[10] P. Ribereau-Gayon, Y. Glories, A. Maujeanand, D. Dubourdieu, Handbook of enology. The chemistry of wine: Stabilization and treatments, 2 (EDP Chichester: Wiley, U.K., 2006)

[11] E. Ronald, R. Nina., W. Robert, A. Keith and G Edward, J. Food Sci. 58(3), 633-637 (1993)

[12] C. Delfini and G. Nicolini, J. Int. Sci. Vigne Vin, 25(1), 1-35 (1991)

[13] P. Cuenat, D. Kobel and E. Zufferey, Bull. OIV 701702, 519-537 (1989)

[14] M. Mietton-Peuchot, V. Milisic and P. Noilet, Desalination 148, 125-129 (2002)

[15] L. Rotaru, Soiuri de viţă de vie pentru struguri de vin, (EDP "Ion Ionescu de la Brad", Iaşi, 2009

[16] S. Rodriguez Mozaz, A. Garcia Sotro, J. Garrido Segovia, C. Ancin Azpilicueta, Food Research Int. 32, 683-689 (1999) 